Вязинкин Алексей Юрьевич, Двухжилова Ирина Владимировна

РАХМАНИНОВСКИЕ МЕСТА В ТАМБОВСКОЙ ОБЛАСТИ: ПЕРСПЕКТИВЫ ИСТОРИКО-

\title{
КУЛЬТУРНОЙ РЕКОНСТРУКЦИИ
}

Проблема охраны традиции, объектов культуры привлекает внимание исследователей к изучению памятных мест как способу реактуализации социальной памяти. Авторами теоретические положения проекта историкокультурной реконструкции "мест памяти" рассматриваются на примере объектов на территории Тамбовской области, связанных с именем С. В. Рахманинова. Определены основные источники историко-культурной реконструкции региональных рахманиновских памятных мест, в которую вошли мемуарная литература, письма, адрес-календари, архивные материалы. Обзор наиболее значимых рахманиновских "мест памяти" впервые включает в себя анализ достоверности факта пребывания композитора в них.

Адрес статьи: www.gramota.net/materials/9/2019/12/5.html

\section{Источник}

\section{Манускрипт}

Тамбов: Грамота, 2019. Том 12. Выпуск 12. С. 34-39. ISSN 2618-9690.

Адрес журнала: www.gramota.net/editions/9.html

Содержание данного номера журнала: www.gramota.net/materials/9/2019/12/

\section{( ) Издательство "Грамота"}

Информация о возможности публикации статей в журнале размещена на Интернет сайте издательства: www.gramota.net Вопросы, связанные с публикациями научных материалов, редакция просит направлять на адрес: hist@gramota.net 
УДК 93(908)

https://doi.org/10.30853/manuscript.2019.12.5

Дата поступления рукописи: 22.10.2019

Проблема охраны традиции, объектов культуры привлекает внимание исследователей к изучению памятных мест как способу реактуализации социальной памяти. Авторами теоретические положения проекта историко-культурной реконструкичи «мест памяти» рассматриваются на примере объектов на территории Тамбовской области, связанных с именем С. В. Рахманинова. Определены основные источники историкокультурной реконструкции региональных рахманиновских памятных мест, в которую вошли мемуарная литература, письма, адрес-календари, архивные материалы. Обзор наиболее значимых рахманиновских «мест памяти» впервые включает в себя анализ достоверности факта пребывания композитора в них.

Ключевые слова и фразы: Сергей Рахманинов; Тамбовская губерния; место памяти; социальная память; виртуальное моделирование; исторически значимые территории; коммеморативные материалы.

Вязинкин Алексей Юрьевич, к. филос. н.

Двухжилова Ирина Владимировна, к.и.н., доцент

Тамбовский государственный технический университет

vyazinkin@yandex.ru; eriniya711971@mail.ru

\section{РАХМАНИНОВСКИЕ МЕСТА В ТАМБОВСКОЙ ОБЛАСТИ: ПЕРСПЕКТИВЫ ИСТОРИКО-КУЛЬТУРНОЙ РЕКОНСТРУКЦИИ}

Исследование выполнено за счет гранта Российского научного фонда (проект № 19-18-00044 «Анализ исторических проиессов памятных мест Тамбовского края, связанных с пребыванием в них известных деятелей России, с использованием технологии виртуального моделирования»).

Актуальность. Современный мир переживает культурную ситуацию утраты коллективной памяти как основы традиции. В этой связи обращение к проблеме культурной значимости памятных мест, в том числе и связанных с пребыванием людей, внесших значительный вклад в различные аспекты культурной, духовной, общественной жизни, представляется актуальным. Тамбовская губерния и область тесно связана с именами В. И. Вернадского, Б. Н. Чичерина, Ф. Ф. Плевако, С. В. Рахманинова и многих других, что актуализирует проведение подобных исследований и здесь. Однако антропогенный ландшафт претерпевает значительные изменения, поэтому аутентичная историко-культурная среда может быть воссоздана только современными виртуальными технологиями [19].

Цель нашего исследования - на основе анализа исторического материала определить и описать наиболее значимые исторические места на территории Тамбовской области, связанные с пребыванием в них выдающегося композитора С. В. Рахманинова, а также рассмотреть полученные данные как коммеморативные материалы для виртуального моделирования памятных мест. Научная новизна исследования состоит в первом подобном научном опыте системного описания рахманиновских мест на территории Тамбовской области, а также в междисциплинарном подходе к обоснованию виртуальной реконструкции памятного места. В работе учитывался методологический опыт, накопленный исследователями «мест памяти» и вопросов социальной памяти. Обоснованием исследования являются теоретические положения работ французского историка, автора концепции «мест памяти» П. Нора [22] и крупнейшего специалиста в области исследования коллективной и исторической памяти, французского социолога М. Хальбвакса [29].

Практическая значимость полученных результатов заключается в их использовании в создании исторически достоверной реконструкции памятных мест на территории Тамбовской области, связанных с именем Рахманинова, реализуемой при помощи программного обеспечения с открытым кодом “OpenSimulator” [17; 18; 30]. Кроме того, выявленные данные могут быть использованы в научной работе и в учебных курсах по отечественной истории, истории градостроительства и краеведению.

В качестве исторических источников для выявления памятных мест, связанных с пребыванием С. В. Рахманинова в Тамбовской губернии, привлечены опубликованные письма, воспоминания, мемуары, адрес-календари Тамбовской губернии. Применительно к Рахманиниане воспоминания являются специфическим источником, так как написаны спустя несколько лет и даже десятилетий с момента описываемых событий. В этом случае есть большая вероятность столкнуться с так называемым «эффектом Манделы», поэтому каждое суждение необходимо перепроверять. Пример такого критического анализа есть в исследовании В. В. Крутова и Л. В. Швецовой-Крутовой [12, с. 78-141].

Выявление и исследование памятных мест на территории современной Тамбовской области, связанных с пребыванием С. В. Рахманинова, началось сравнительно недавно. Большее внимание традиционно уделяется творчеству композитора и его биографии. Однако следует выделить несколько работ, в которых даны обоснованные данные о тамбовских «местах памяти» великого композитора. Таких мест несколько: имение Сатиных Ивановка Тамбовского уезда $[8 ; 10 ; 12 ; 14]$, Рахманиновых - Знаменское Козловского уезда [10; 14], Комсиных - Громок Тамбовского уезда [14], музыкальное училище в Тамбове [9; 10].

Другие адреса, упоминания о которых мы находим в работах краеведов, нуждаются в дальнейшей проверке. Но для исторической памяти важно сохранить исторический облик города в целом. 
Бесспорными по факту пребывания там С. В. Рахманинова являлись имения Знаменское Козловского уезда и Ивановка Тамбовского, здания железнодорожных вокзалов в Тамбове, Козлове и на станции Ржакса, музыкального училища. Указываются как связанные с посещением композитора в Тамбове здание присутственных мест, торговый дом А. М. Шоршорова, дворянское собрание, гостиница Михайлова, дом РостовцевойСкалон $[9$, с. 22], о степени верификации этой информации речь будет ниже. С большой вероятностью к рахманиновским местам в губернском Тамбове можно отнести дома, в которых жили или квартировали друзья и близкие родственники композитора, а именно: дома Полубояриновых, Турчаниновой на Араповской улице (М. Горького), Егорова и Тенис на Дубовой (Комсомольская). Кроме того, О. А. Казьмин указал ещё адрес дома Комсина по адресу Красноармейская площадь, 7 [Там же, с. 8].

Проанализируем рахманиновские места по сохранности, степени достоверности идентификации и возможности виртуального моделирования.

Имение Знаменское Козловского уезда - «вторая родовая усадьба Рахманиновых» [14, с. 307] - была приобретена Г. И. Рахманиновым в 1761 г. Здесь родился отец Сергея Рахманинова, а он сам впервые приехал в Знаменское в 1886 г. По мнению биографов, с 1890 г. летние месяцы С. Рахманинов проводил там у бабушки В. В. Рахманиновой $[10$, с. 39-40; 28, с. 52]. Эти данные подтверждаются и источниками личного происхождения [24, с. 70$]$.

Описание имения имеется во множестве воспоминаний, проанализированных В. А. Кученковой и др. [14, с. 308]. Кроме того, сохранилось несколько фотографий с отдельными видами Знаменского. На основании этих данных возможно только приблизительное создание чертежно-картографического изображения местности, в большей степени вероятное, чем достоверное. Виртуальное моделирование в этом случае представляется нецелесообразным до получения более конкретных данных, которыми могли бы стать планы усадьбы в фондах Государственного архива Тамбовской области (ГАТО). Однако на данный момент они не выявлены.

Особое место в числе культурных объектов Тамбовской области, связанных с именем композитора, занимает достопримечательное место Ивановка. Это родовая усадьба семьи Сатиных, родственников Рахманинова. С этим памятным местом связаны не только весьма значимые главы жизни Сергея Васильевича, но и существенная часть его творческого наследия.

Впервые в Ивановку к родственникам Рахманинов приехал весной 1890 г. и провёл там «необыкновенное лето» [28, с. 36]. Абсолютно достоверным является утверждение, что почти каждый год Сергей Васильевич проводил лето в Ивановке. Важнейшим фактом, подтверждающим глубокую привязанность композитора к Ивановке, было прошение о внесении его в родословную книгу потомственных дворян именно Тамбовской губернии. В Государственном архиве Тамбовской области сохранилось «свидетельство» Тамбовского Дворянского Депутатского Собрания от 5 июня 1895 г. о внесении имени Сергея Васильевича Рахманинова «в шестую часть дворянской родословной книги» [Цит. по: 10, с. 68].

В 1902 г. Рахманинов женился на Наталье Сатиной, дочери владельца Ивановки и двоюродной сестре композитора. С тех самых пор композитор всё больше времени проводил в Ивановке, а по сути связал свою жизнь с этим местом. Помимо творческой работы, Рахманинов взял на себя значительную часть забот о ведении хозяйства. По воспоминаниям приятеля Рахманинова, знаменитого композитора и пианиста А. Б. Гольденвейзера, Сергей Васильевич «в течение ряда лет, отказывая себе во многом», почти всё заработанное тратил на имение, в том числе и погашение старых долгов [6, с. 425]. Хозяйственная и творческая жизнь композитора не мешали, а, напротив, взаимно дополняли друг друга.

Несмотря на противоречивые свидетельства и воспоминания, Рахманинов, по мнению О. Казьмина и Д. В. Калашникова, никогда не был владельцем имения. В 1911 г. Ивановка перешла в собственность В. А. Сатина и Н. А. Рахманиновой, жены Сергея Васильевича [10, с. 55]. Однако О. фон Риземан записал: «...незадолго до начала мировой войны Рахманинов выкупил Ивановку у своего свёкра (тестя. - $A$. В., И. Д.) и совместно с шурином взял на себя управление имением» $[24$, с. 160]. Впрочем, совершить сделку купли-продажи он мог и на имя супруги.

Трагические события 1917 г. семья Рахманиновых переживала сначала в Ивановке, затем в Москве. Сергей Васильевич не мог принять русскую революцию, видя в ней гибель дорогой ему прежней культуры и цивилизации. В декабре 1917 г. он получил приглашение из Стокгольма, и семья уехала из России, как оказалось, навсегда. А дворянское имение было разрушено.

Реставрация объектов на территории памятного места началась после постановления бюро Тамбовского областного комитета КПСС и облисполкома от 29 июля 1968 г. № 550 «Об увековечении памяти С. В. Рахманинова». Существует как минимум два свидетельства об источнике чертежей и планировок реконструкции «Ивановки». Знаменитая оперная певица И. К. Архипова, фонд которой финансировал реконструкцию, вспоминала, что план-рисунок был набросан самим Рахманиновым в Швейцарии [3, с. 11]. Подробное описание Ивановки было сделано двоюродной сестрой Рахманинова Софьей Александровной Сатиной по просьбе тамбовского композитора и музыковеда Н. Н. Емельяновой $[20$, с. 3]. Генеральный план по воссозданию памятного места был утвержден в 1970 г. на основе проекта московского архитектора В. М. Белоусова, который опирался на план-рисунок из архива С. А. Сатиной [4, с. 19]. Однако в исследовательской работе Д. В. Калашникова и О. А. Казьмина утверждается, что план усадьбы и села Ивановка принадлежали самой Софье Александровне [10, с. 95-96]. Проектная работа Белоусова была начата с реконструкции флигеля, в котором жила семья Рахманиновых.

В 1978 г. на территории Ивановки был создан Дом-музей С. В. Рахманинова, преобразованный в 1987 г. в Музей-усадьбу. За последние три десятилетия на территории Ивановки были воссозданы гараж, кладовая, усадебный дом, садовый домик, дворовая изба. Кроме того, создан кабинет-музей внучатого племянника 
композитора - ученого Ю. П. Рахманинова, открыты сцены Зеленого театра, экспозиция А. Сатина и М. Шаталиной, проводятся научные конференции памяти композитора, издаётся альманах «Ивановка».

Тенденцией последних лет в России стало формирование культуры памятных мест. И в этом смысле «Ивановка» находится в авангарде данного направления историко-культурного развития страны. В 2018 г. «Имение дворян Сатиных “Ивановка” у успешно прошло государственную историко-культурную экспертизу и было рекомендовано к включению в единый государственный реестр объектов культурного наследия (памятников истории и культуры) народов Российской Федерации (с присвоением статуса музея-заповедника). Исторически и культурно значимыми признаны не только, собственно, «объекты культурного наследия», но и элементы объёмно-пространственной структуры имения, ландшафтные элементы исторической среды.

Несмотря на физическое восстановление усадебных объектов Ивановки, актуальной является и виртуальная реконструкция памятного места. В данном случае для виртуальной модели есть все необходимые данные, в том числе поверочная опись государственного Дворянского земельного банка, план строений, фотографии Ивановки до её восстановления из личного фонда Н. Н. Емельяновой [7].

Вокзалы в Козлове и Тамбове не могли остаться в стороне от маршрутов С. В. Рахманинова. Через козловскую станцию пролегал маршрут в Знаменское, а позже, когда отец композитора поселился в уездном Козлове, он навещал и его $[11$, с. 386]. К сожалению, адрес не установлен. Известный мичуринский краевед М. П. Белых даже не упоминает имени Василия Аркадьевича при описании рода Рахманиновых как проживающего в Козлове или уезде [5, с. 66-69].

В старинном Козлове (Мичуринске) два железнодорожных вокзала: тупиковый дальнего направления, открытый в 1866 г. (Мичуринск-Уральский), и транзитный южного направления, открытый в 1886 г. (Мичуринск-Воронежский). К сожалению, в источниках не уточняется вокзал прибытия, но не исключено, что Рахманинов посетил и тот, и другой. Оба здания сохранились, хоть и со значительными изменениями. Но окружающая историческая среда утрачена.

В значительной мере изменился облик железнодорожного вокзала в Тамбове. Городская историческая среда XIX века в районе вокзала угадывается лишь в нескольких сохранившихся строениях.

Значительное время пребывания пассажиров в этом месте диктовалось особенностью железнодорожного сообщения: происходило «переформирование камышинского поезда» в течение 3-х часов на станции Тамбов [9, с. 7]. Это время позволяло С. В. Рахманинову «завтракать в станционном ресторане», гулять «по Привокзальной площади или по Дворянской», навещать родных или друзей [Там же]. О. Казьмин приводит отрывок из письма Рахманинова Л. Д. Ростовцевой-Скалон от 15 апреля 1902 г., в котором рассматривается возможность навестить Людмилу Дмитриевну и её супруга в доме на улице Тёплой (по соседству с Комсиными и Кондыревыми) именно в момент длительной стоянки, кстати, накануне женитьбы на Н. А. Сатиной [10, с. 67]. Однако об осуществлении этого намерения ничего не известно.

На вокзале в Ржаксе, который не сохранился, как и историческая среда посёлка в целом, С. В. Рахманинов бывал неоднократно. Именно здесь он сходил с поезда Москва-Камышин и садился на него, сюда доставлялись сельскохозяйственные машины, породистые животные. Адрес «ст. Ржакса Тамбово-Камышинской ж.д. Ивановка» был указан Рахманиновым и при покупке рояля [27, с. 206].

Кстати, в имении было 2 рояля. Один из них был приобретён летом 1906 г., второй доставлен зимой 1907 г. «Судьба» инструментов прослеживается по воспоминаниям старожилов и в мемуарах Я. И. Фарбера. В 1918 г. инструменты были переданы Ивановской начальной школе и Степановскому детскому дому. Первый «был разрушен» [10, с. 143], а следы второго затерялись, пока в 1956 г. он не был обнаружен в подсобном помещении Ржаксинского дома культуры Я. И. Фарбером совместно с «секретарём райкома партии по идеологии» и директором «культурного дома» [27, с. 205]. Принадлежность рояля дому Рахманинова подтвердили краеведы Б. Мартынов, Н. Никифоров, О. Казьмин. Но для Фарбера «особую ценность представляло подтверждение подлинности находки» В. Т. Шмелёвым, который был сыном истопника Ивановского имения [Там же, с. 206]. Помимо прочего Шмелёв рассказал почти анекдотичную историю, связанную с покупкой рояля: когда инструмент был установлен, Рахманинов «сел к роялю и, энергично потерев руки, стал ими быстро проходить от края до края клавиатуры. Один нетерпеливый конюх возьми да и спроси: барин, а ты играть-то умеешь иль только учишься? Сергей Васильевич расхохотался и тут же сыграл нам “Комаринскую”» [Цит. по: Там же].

В 1958 г. рояль был передан в краеведческий музей [10, с. 143]. В восстановленной же усадьбе экспонируется рояль, принадлежавший С. И. Комсину, на котором Рахманинов «музицировал» во время своих визитов в его городской дом [9, с. 8$]$.

В воспоминаниях А. Ф. Гёдике фигурирует ещё одна железнодорожная станция, которую хотя бы однажды, в 1913 г., посетил С. В. Рахманинов: «Приехав на большую стацию Сампур, я увидел в окно автомобиль и в нём Сергея Васильевича за рулём. Его двоюродная сестра Софья Александровна вошла в эту минуту ко мне в вагон и предложила быстро собираться и ехать дальше с Сергеем Васильевичем в машине» [Цит. по: 10, с. 61]. От всего комплекса строений, составлявших станцию Сампур (п. Сатинка), сохранилась лишь водонапорная башня.

В силу стратегической значимости железнодорожных станций имеются все необходимые документы (планы, описания, фотографии), позволяющие виртуальную реконструкцию не только привокзальных строений, но и прилегающей территории. Такая реконструкция имеет более широкое значение, чем памятное место, связанное с пребыванием одного человека, и может быть использована как фрагмент воссоздания облика населённого пункта в определённую историческую эпоху.

Целый ряд общественных зданий в Тамбове связан с инспекцией С. В. Рахманиновым музыкального училища в мае 1909 г. Инициатором инспектирования был тогдашний тамбовский губернатор Н. П. Муратов, который в своих мемуарах много внимания уделил «преследованию» Старикова [16, с. 66-70, 262-273]. Поводом 
к этому было вовсе не то, что музыкальное училище «работало под руководством С. М. Старикова плохо и ничего не давало городу» [9, с. 12]. Сам Муратов абсолютно откровенно дал понять, что причиной всему было еврейское происхождение Соломона Моисеевича [16, с. 257-258, 263]. Впрочем, «еврейский вопрос» занимал не только тамбовского губернатора. В 1912 г. подобная история произошла с «однокашником» Рахманинова М. Л. Пресманом. И в том случае Рахманинову удалось установить «полную правоту Пресмана» [24, с. 295], однако они оба вынуждены были уйти в отставку [15, с. 80-82]. В случае же со Стариковым «полное поражение» признал губернатор Муратов [16, с. 262].

Назначенный помощником председателя Музыкального общества Рахманинов с инспекцией прибыл в Тамбов 5 мая 1909 г. и посетил училище. В своём отчёте герцогине Е. Г. Саксен-Альтенбургской он отметил хорошее впечатление от училища, несмотря на внезапность проверки [15, с. 74-75]. С отчётом о результатах ревизии Рахманинов, по мнению Казьмина, посетил дом губернатора [9, с. 13], находившийся на берегу Цны и граничивший с городским сквером и «садом Купеческого клуба». Скорее всего, путь Рахманинова мог пролегать именно через городской сквер. Однако встреча с Муратовым не состоялась [25]. Вероятно, мнение инспектора до губернатора было доведено официально руководством Императорского русского музыкального общества.

А вот факт дружеского ужина с педагогами Музыкального училища в ресторане гостиницы И. И. Михайлова освещён в письме А. Б. Гольденвейзера, на которое ссылается О. А. Казьмин [9, с. 13-14].

Здания Музыкального училища и гостиницы Михайлова сохранились с изменениями во внешнем облике. Историческая среда вокруг претерпела значительные изменения с развитием городской инфраструктуры Тамбова за прошедшее столетие. Однако оба этих здания запечатлены на фотографиях с начала XX в. разных ракурсах, и вполне возможно их включение в виртуальную реконструкцию исторической части города.

Дом губернатора, находившийся в глубине городского сквера, на фотографии попадал не часто. Однако в мемуарах губернатора Муратова есть подробное описание его внешнего облика, внутренней планировки и окружающего ландшафта, что позволило бы создать изометрический чертёж, а на его основе и виртуальную реконструкцию.

Сохранились в исторической части города и другие общественные здания, упоминаемые О. А. Казьминым как связанные с именем С. В. Рахманинова. Это здание присутственных мест, дом Шоршорова, где, возможно, были приобретены рояли, и Дворянское депутатское собрание. И, если первые два объекта с большой долей вероятности мы можем считать посещаемыми Рахманиновым, то для включения здания Дворянского собрания в этот список приводятся спорные аргументы. Последнее здание Дворянства было построено в 1897 г. [13, с. 130-131], тогда как прошение о внесении имени С. В. Рахманинова в родословную книгу потомственных дворян Тамбовской губернии было удовлетворено в 1895 г. [9, с. 8]. Однако мы не можем отрицать возможность посещения композитором нового здания собрания по какому-либо другому поводу, ведь там проходили концерты, в том числе с участием Ф. Шаляпина и А. Зилоти, работал кинотеатр «Коллизей».

Справедливости ради надо отметить, что, помимо магазина Ф. Д. Рорбаха в торговом доме Шоршорова, в городе были и другие крупные торговые заведения, занимавшиеся продажей фирменных роялей и пианино [13, с. 127].

Что касается частных визитов С. В. Рахманинова в Тамбове, то тут можно довериться мнению С. А. Сатиной, сестры Н. А. Рахманиновой. Она утверждала, что во время редких посещений губернского центра Сергей Васильевич «останавливался у Александра Ивановича и Марии Валериановны Сатиных, с которыми был очень дружен» [Цит. по: 9, с. 10]. Как большинство уездных помещиков, Сатин не имел собственного дома в городе, пользуясь съёмным жильём. Так, в 1909 г. во время инспектирования Рахманиновым Музыкального училища Сатины «квартировали» на улице Дубовой в доме Егорова [10, с. 10], владельца мукомольного заведения. Затем семья перебралась через дорогу в дом Н. Т. Тенис [23, с. 71]. В адрес-календаре за 1914 г. в качестве места проживания уездного предводителя дворянства коллежского асессора А. И. Сатина значилось улица Архангельская, домовладение Полубояриновой [1, с. 227]. В то же время Казьмин, Фарбер и ряд других краеведов указывают адрес другого дома Полубояриновых - на Араповской, 23 - как посещавшегося Рахманиновым [9, с. $11 ; 27$, с. 15]. На данном этапе исследования это противоречие неразрешимо. Дом Полубояриновых на бывшей улице Араповской утрачен. Установить же точный адрес по бывшей Архангельской (ул. Рабочая) пока не удалось. Вероятность того, что и этот дом не сохранился, весьма велика.

Ещё один адрес на Араповской улице не вызывает сомнений. Это уже упоминавшаяся бывшая усадьба К. Н. Турчанинова, в которую входило три дома, использовавшихся как доходные. В доме-флигеле в глубине двора проживали кузины Рахманинова со стороны отца - М. А. Турчанинова и Л. А. Вибор. Об этом писал А. К. Турчанинов в 1963 г.: «Сергей Васильевич приехал к нам один, а потом в этот день или на следующий за ним на машине приехал Сатин Александр Иванович с женой...» [Цит. по: 9, с. 10]. Эти дома, равно как дома Егорова и Тенис на бывшей Дубовой, сохранились. Однако состояние их вызывает беспокойство. Хотя они в совокупности с окрестными строениями являются островками аутентичной застройки конца XIX - начала XX века и подлежат сохранению.

Среди тамбовских знакомых нельзя обойти вниманием и Л. Д. Ростовцеву, Лёлю Скалон, среднюю из трёх сестёр, которые провели памятное лето 1890 г. в Ивановке в компании с Сатиными, Зилоти и С. Рахманиновым. Выйдя замуж, Людмила поселилась в Тамбове. В упоминавшемся письме от 15 апреля 1902 г. Рахманинов спрашивал разрешения навестить их с мужем: «...в Тамбове поезд стоит что-то около трёх часов... я собираюсь в это свободное время заехать к Вам, на Вас посмотреть, посидеть и кофею выпить, если дадите» [Цит. по: Там же, с. 7]. Высказанное намерение многими исследователями толковалось как возможность посещения, пока «от сказанного с условием» не пришли «к сказанному безусловно». 
Теперь встречается утверждение, что Рахманинов бывал в гостях у Ростовцевых в Тамбове, что, однако, не подтверждается другими источниками, в том числе и воспоминаниями самой Л. Д. Ростовцевой-Скалон.

Есть и ещё один нюанс: доходный дом А. Ф. Назарьева, в котором квартировали Ростовцевы, был построен в 1904-1912 гг. [13, с. 187; 14, с. 302; 23, с. 86], следовательно, посетить его в 1902 г. С. В. Рахманинов не мог.

«Напротив дома Ростовцевых в угловом двухэтажном особняке... проживал друг семьи Сатиных и Рахманиновых Сергей Иванович Комсин» [9, с. 8]. Этот дом, как и весь квартал, был снесён. Постоянно по адресу угол Большой и Тёплой жила семья родного брата супруги Комсина Е. П. Кондырева, члена Тамбовской губернской земской управы в 1892-1917 гг. [1, с. 196; 2, с. 9 (60); 21, с. 410]. Дом Комсина на бывшей Инвалидной площади, упоминавшийся выше, не сохранился. Данные для виртуальной реконструкции кварталов улицы Тёплой (с 1914 г. - Лермонтовской) имеются в недостаточном количестве, несмотря на то, что до сих пор сохраняются здания дореволюционной застройки, в том числе упомянутый доходный дом Назарьева.

Более тесные взаимоотношения С. В. Рахманинов мог иметь с Виктором Ивановичем Комсиным, так как дочь его супруги - Мария Валериановна - была замужем за А. И. Сатиным. Воспитанник семьи Комсиных В. Е. Карандеев вспоминал, что в усадьбе «Громок» Сампурской волости Тамбовского уезда бывал С. В. Рахманинов, который «приезжал на автомобиле за практическими советами к Александру Ивановичу Сатину» [14, с. 291]. Об одном визите мы читаем и в воспоминаниях А. А. Трубниковой: «Не помню точно, в каком году, в Ивановке решили совершить длительную прогулку в автомобиле. Порядок установили следующий: заехать в Лукино за А. И. Сатиным, затем к Комсиным...» [26, с. 140].

Очень вероятно, что во время визитов в «Громок» Рахманинов мог заезжать и к С. И. Комсину, чья гавриловская усадьба находилась менее чем в двух километрах. И ещё более велика вероятность, что Рахманинов был в Гавриловке летом 1913 г., когда умер В. И. Комсин. Виктора Ивановича похоронили возле церкви в родовом имении Комсиных, которым и была Гавриловка. Косвенно подтверждением этой версии может быть воспоминание о встрече на вокзале в Сампуре А. Ф. Гёдике (В. И. Комсин скончался 24 июня 1913 г., Гёдике приехал «в начале июля»).

Несмотря на то, что в Сампуре бережно хранят память о своих помещиках Комсиных, от усадебных домов остались лишь воспоминания да старые фотографии. Неизменным остался лишь огромный гранитный надгробный памятник В. И. Комсину на бывшем церковном кладбище в Гавриловке. В качестве объектов виртуальной реконструкции Гавриловка и Громок имеют большой потенциал, как и село Сампур, к которому они примыкают.

Подводя итог, следует отметить, что исторически достоверными рахманиновскими местами на территории города Тамбова являются музыкальное училище (сейчас - Тамбовский государственный музыкальнопедагогический институт им. С. В. Рахманинова (ул. Советская, д. 87)); усадьба К. Н. Турчанинова на Араповской улице (ул. М. Горького, д. 41); гостиница Михайлова, позже - Никольских (ул. Интернациональная, 22); а на территории области - «Имение дворян Сатиных “Ивановка”», опыт виртуальной и реальной реконструкции которого был бы невозможен без исторического исследования.

В то же время ряд позиций на карте рахманиновских мест требуют дальнейшей разработки, подбора и анализа материалов для историко-культурной реконструкции.

Определены степень достоверности идентификации объектов на территории Тамбовской области как рахманиновских мест, степень их коммеморативной значимости. Необходимо отметить, что использование современных технологий позволяет создавать принципиально новые формы коммеморативных практик, цементирующих сознание общества и коллективную память на основе реактуализации гражданской и культурной идентичности. И в этом смысле наиболее существенной историко-культурной перспективой нашего исследования является возможность виртуальной реконструкции рахманиновских мест и создание виртуального музея.

\section{Список источников}

1. Адрес-календарь и памятная книжка Тамбовской губернии. 1914 г. Тамбов, 1914. 1153 с.

2. Адрес-календарь и справочная книжка Тамбовской губернии. 1913 г. Тамбов, 1913. 775 с.

3. Архипова И. Сад Рахманинова // Ивановка. Времена. События. Судьбы: альманах. М.: Изд-во Фонда Ирины Архиповой, 2003. С. 10-13.

4. Белоусов В. Реставрация дома С. В. Рахманинова // Музыкальная жизнь. 1971. № 14.

5. Белых М. П. Козловские фамилии. Мичуринск: Изд. дом «Мичуринск», 2005. 95 с.

6. Гольденвейзер А. Б. Из личных воспоминаний о С. В. Рахманинове // Воспоминания о Рахманинове: в 2-х т. М.: Музыка, 1988. Т. 1. С. 401-426.

7. Государственный архив Тамбовской области (ГАТО). Ф. Р-5345.

8. Емельянова Н. Н. Ивановка в жизни и творчестве Рахманинова. Воронеж: Центрально-Чернозёмное книжное издательство, 1984. 159 с.

9. Казьмин О. А. Рахманиновские места в Тамбове. Тамбов: Пролетарский светоч, 2002. 23 с.

10. Казьмин О. А., Калашников Д. В. «В Ивановку я всегда стремился...»: Сергей Рахманинов на Тамбовской земле. Воронеж: Центр духовного возрождения Черноземного края, 2003. 272 с.

11. Казьмина Е. О. «Здесь хорошо...»: С. В. Рахманинов и Тамбовский край // Тамбов в прошлом, настоящем и будущем: материалы VIII Всероссийской научной конференции, посвящённой 100-летию событий Гражданской войны в России: трагедии и драмы выбора исторического пути развития (г. Тамбов, 26 апреля 2018 г.). Тамбов: ТПС, 2018. С. 383-387.

12. Крутов В. В., Швецова-Крутова Л. В. Мир Рахманинова: в 3-х кн. Тамбов: Юлис, 2006. Кн. 2. 496 с.

13. Кученкова В. А. Неизвестный Тамбов. Тамбов: Пролетарский светоч, 1993. 221 с.

14. Кученкова В. А. Усадьбы Тамбовской губернии. Тамбов: Тамбовполиграфиздат, 2009. 392 с.

15. Михеева М. В. Архив С. В. Рахманинова в Петербурге как источник изучения творчества и биографии композитора. Тамбов - Ивановка: Музей-усадьба С. В. Рахманинова «Ивановка», 2012. 208 с. 
16. Муратов Н. П. Записки тамбовского губернатора. Тамбов: Пролетарский светоч, 2007. 436 с.

17. Немтинов В. А., Борисенко А. Б., Горелов А. А., Немтинова Ю. В., Трюфилькин С. В. Виртуальный музей как одно из направлений развития музейной педагогики // Вопросы современной науки и практики. Университет им. В. И. Вернадского. 2017. № 4 (66). С. 137-143.

18. Немтинов В. А., Горелов А. А. Моделирование объектов культурно-исторического наследия - основа клиометрических исследований // Клио. 2010. № 4 (51). С. 3-7.

19. Немтинов В. А., Горелов А. А., Острожков П. А., Манаенков А. М., Немтинова Ю. В., Морозов В. В., Горелов И. А., Немтинов К. В. Информационные технологии при создании пространственно-временных моделей объектов культурно-исторического наследия: монография. Тамбов, 2013. 213 с.

20. Николаева Н. День Рахманинова в Ивановке // Музыкальная жизнь. 1970. № 19.

21. Новикова Е. В. История тамбовской семьи Кондыревых // Тамбов в прошлом, настоящем и будущем: материалы VIII Всероссийской научной конференции, посвящённой 100-летию событий Гражданской войны в России: трагедии и драмы выбора исторического пути развития (г. Тамбов, 26 апреля 2018 г.). Тамбов: ТПС, 2018. С. 407-412.

22. Нора П. Проблематика мест памяти // Франция-память: сборник. СПб.: Издательство Санкт-Петербургского университета, 1999. С. 17-50.

23. Прогулки по старому Тамбову: иллюстрированный путеводитель / авт.-сост. В. А. Ермаков, Ю. К. Щукин, А. А. Горелов. Тамбов: Пролетарский светоч, 2011. 192 с.

24. Рахманинов С. В. Воспоминания, записанные Оскаром фон Риземаном. М.: АСТ, 2018. 320 с.

25. Рахманинов С. В. Письма [Электронный ресурс]. URL: https://senar.ru/letters/391 (дата обращения: 23.07.2019).

26. Трубникова А. А. Сергей Рахманинов // Воспоминания о Рахманинове: в 2-х т. М.: Музыка, 1988. Т. 1. С. 116-145

27. Фарбер Я. И. Улица родная, Араповская улица моя. Тамбов: Пролетарский светоч, 2010. 216 с.

28. Федякин С. Р. Рахманинов. М.: Молодая гвардия, 2014. 478 с.

29. Хальбвакс М. Коллективная и историческая память // Неприкосновенный запас. 2005. № 2-3 (40-41). С. 8-27.

30. Nemtinov V. A., Gorelov A. A., Nemtinova Yu. V., Borisenko A. B. Visualization of a virtual space and time model of an urban development territory // Scientific Visualization. 2016. Vol. 8. Iss. 1. P. 120-132.

\title{
RACHMANINOFF'S PLACES IN TAMBOV REGION: PROSPECTS FOR HISTORICAL AND CULTURAL RECONSTRUCTION
}

\author{
Vyazinkin Aleksei Yur'evich, Ph. D. in Philosophy \\ Dvukhzhilova Irina Vladimirovna, Ph. D. in History, Associate Professor \\ Tambov State Technical University \\ vyazinkin@yandex.ru; riniya711971@mail.ru
}

The problem of cultural heritage preservation is associated with the necessity to study commemorative places as a means to re-actualize social memory. Theoretical provisions of a project of historical and cultural reconstruction of commemorative places are considered by the example of cultural objects in Tambov region associated with S. V. Rachmaninoff's name. The paper identifies the basic sources of historical and cultural reconstruction of Rachmaninoff's commemorative places, which include memoir literature, letters, official directories, archival materials. A survey of the most important Rachmaninoff's commemorative places for the first time includes an analysis to show whether there is reliable evidence of the composer's stay at a certain place.

Key words and phrases: Sergei Rachmaninoff; Tambov province; memorial place; social memory; virtual modelling; historically valuable places; commemorative materials.

УДК 9.908

https://doi.org/10.30853/manuscript.2019.12.6

Дата поступления рукописи: 13.10 .2019

Статья раскрывает основные этапы, методы и характер борьбы с социальными болезнями в первой половине XX века в Горном Алтае. Авторами на широком круге источников из коллекиий региональньхх архивов выявлены условия распространения болезней, обусловленные уровнем жизни населения региона; определены особенности организачии медицинской и профилактической помощи по лечению и предотвращению заболеваемости в различные периоды; охарактеризованы участие и специфика работы общественных организациий по борьбе с социильными болезнями в нацииональном регионе.

Ключевые слова и фразы: социальная история; Горный Алтай; национальный регион; история здравоохранения; социальные болезни; трахома; сифилис; туберкулез.

Гончарова Ольга Александровна, д.и.н., профессор

Анкудинова Татьяна Валерьевна, к.и.н., доцент

Горно-Алтайский государственный университет

Goa10@yandex.ru; 15fduecnf@mail.ru

\section{БОРЬБА С СОЦИАЛЬНЫМИ БОЛЕЗНЯМИ В ГОРНОМ АЛТАЕ В ПЕРВОЙ ПОЛОВИНЕ ХХ ВЕКА}

Такое явление, как социальные болезни, вернулось в российскую повседневность в последнее десятилетие. В России начал вновь фиксироваться рост, например, туберкулеза. Социальными эти болезни названы потому, 